\title{
APLICAÇÃO DO ÍNDICE DE GRADIENTE DO CANAL NA ANÁLISE GEOMORFOMÉTRICA DA BACIA DO RIO BONITO (PETRÓPOLIS, RJ)
}

\author{
Daniele Pereira Pecorella ${ }^{\text {(a) }}$, Laura Delgado Mendes ${ }^{(b)}$ \\ (a) DGEO/Instituto Multidisciplinar, Universidade Federal Rural do Rio de Janeiro, dani_pecorella@yahoo.com.br \\ (b) DGEO/Instituto Multidisciplinar, Universidade Federal Rural do Rio de Janeiro, lauradmendes@ gmail.com
}

EIXO: SISTEMAS GEOMORFOLÓGICOS: ESTRUTURA, DINÂMICAS E PROCESSOS

\begin{abstract}
Resumo
O objetivo desse trabalho é apresentar os resultados da aplicação do índice de gradiente do canal (SL) na bacia do rio Bonito (Petrópolis-RJ) utilizando estudos prévios com abordagem morfotectônica. $\mathrm{O}$ índice de gradiente do canal permite a análise geomorfométrica dos perfis longitudinais dos rios e, por sua vez, possibilita identificar e quantificar anomalias associadas à controles litológicos e/ou estruturais e, especialmente, neotectônicos. Os dados de sete canais (rio principal e seis afluentes da margem direita) para o SL Total e doze pontos para o SL Trecho foram obtidos a partir de carta topográfica na escala de 1:10000, com auxílio de curvímetro, e calculados em planilha electrônica. Os índices SL mais elevados coincidem com as marcantes rupturas observadas nos perfis longitudinais dos canais que indicam o controle tectônico-estrutural na área, que se reflete na sua compartimentação morfotectônica, e em especial na configuração da rede de drenagem.
\end{abstract}

Palavras chave: geomorfometria. índice de gradiente do canal. perfil longitudinal. morfotectônica

\section{Introdução}

O sistema fluvial é um elemento importante para a análise das alterações da paisagem combinadas à evolução tectônica já que é altamente sensível à transmissão de imputs desencadeadores de mudanças ambientais (THOMAS \& ALLISON, 1993). Diante disso, torna-se o segmento mais vulnerável a qualquer tipo de alteração, em escala temporal que pode variar entre alguns milhões a milhares de anos e séculos a décadas, e o entendimento de sua dinâmica mostra-se de extrema importância para todos os estudos que envolvem a análise do meio físico.

O índice de gradiente do canal (stream gradient index) ou SL (Slope vs Length) proposto por Hack (1973), sendo também denominado "índice de Hack" ou relação Declividade-Extensão (RDE) (ETCHEBEHERE et al., 2004) permite a análise geomorfométrica dos perfis longitudinais dos rios, considerando o que se espera de um perfil de equilíbrio. Por sua vez, essa análise possibilita identificar e quantificar anomalias, ou seja, condições de desequilíbrio, associadas à controles litológicos e/ou estruturais e, especialmente, reativações tectônicas. 
O objetivo desse trabalho é apresentar os resultados da aplicação do índice de gradiente do canal na bacia hidrográfica do rio Bonito (Petrópolis-RJ) utilizando como base os estudos morfotectônicos realizados previamente por Mendes et al. (2007) que indicam o controle tectônico-estrutural na área, que se reflete na sua compartimentação morfotectônica e na configuração da rede de drenagem.

\section{Materiais e Métodos}

A área de estudo é a bacia hidrográfica do rio Bonito, sub-bacia do rio Piabanha (Petrópolis-RJ), que compreende uma área de, aproximadamente $60 \mathrm{~km}^{2}$ situada no Terreno Oriental da Faixa Ribeira (HEILBRON et al., 1999), com ocorrência predominante dos granitóides Serra dos Órgãos (ALMEIDA, 2000). O Complexo Rio Negro ocorre apenas na área de confluência com o rio Preto, o qual está encaixado na Zona de Cisalhamento Rio Preto (Almeida, 2000). Geomorfologicamente, situa-se no Domínio Morfoestrutural do Planalto Atlântico, na Região do Planalto e Escarpas da Serra dos Órgãos, posicionada entre as Unidades Geomorfológicas de colinas/morros e maciços costeiros e Alinhamento de cristas Paraíba do Sul (SILVA, 2002).

As anomalias dos perfis longitudinais dos rios foram identificadas e quantificadas a partir da aplicação do índice de gradiente do canal, como proposto por Hack (1973), que considera SL = $\Delta \mathrm{h} / \Delta \mathrm{l} * \mathrm{~L} ;$ onde $\mathrm{SL}=$ índice; $\mathrm{h} / \mathrm{l}=$ declividade; e $\mathrm{L}=$ extensão acumulada. Essa análise é significante pois revela a energia do canal para transporte de material, assim como as características de resistência ao fluxo (HACK, 1973).

A obtenção dos dados teve como base cartas topográficas na escala de 1:10 000, produzidas pela da Prefeitura Municipal de Petrópolis, com auxílio de curvímetro. Os canais de drenagem foram selecionados a partir de estudo realizado por Mendes et al. (2007) e que identifica rupturas importantes nos perfis longitudinais dos rios associados à evolução morfotectônica da área. Os dados foram inseridos posteriormente em uma planilha eletrônica para fins de realização dos cálculos da amplitude (h), extensão média, extensão acumulada (L), declividade (h/l) e, por fim, o índice SL. Optou-se por quantificar o índice total (SL Total) e por trecho (SL Trecho) a fim de melhor observar as rupturas de declive existentes. Foram analisados sete canais (rio principal e seis afluentes da margem direita) para o SL Total e doze pontos para o SL Trecho. 


\section{Resultados e Discussão}

Os resultados do índice de gradiente de canal (SL) variam entre 2 e 545 (Tabelas 1 e 2).

Como pode ser observado na Tabela 1, os índices totais (SL Total) apresentam-se mais elevados na parte superior da bacia, nas cabeceiras do canal principal (Rio Bonito e Maria Antônia), assim como num dos canais afluentes analisados (Brejal). Tais índices também coincidem com os obtidos em alguns trechos (SL Trecho) (Tabela 2) como nos cursos inferiores dos rios Bonito e Brejal, ambos associados a uma importante ruptura de declive que promove um desnivelamento de 300 metros no canal principal (MENDES et al., 2007). Os autores observam a presença de um alto topográfico nessa área, com estruturação que define a orientação e a presença de anomalias na rede de drenagem, identificadas e medidas no presente trabalho pelo índice de gradiente de canal.

Segundo Zhang et al. (2003), contatos litológicos e falhas podem afetar localmente a forma dos perfis longitudinais e, por sua, vez, do índice SL, com valores anômalos elevados. No caso da área de estudo tais anomalias parecem estar diretamente relacionadas com as estruturas já que a litologia é predominantemente homogênea, como observado por Mendes et al. (2007).

A análise do SL por trechos (Tabela 2) apresenta algumas disparidades quando observados os cursos superiores e inferiores dos canais e que revelam a presença das marcantes rupturas nos seus perfis longitudinais. Destacam-se os índices SL do rio Bonito, Nunes e Matilde, com índices nos trechos inferiores que alcançam aproximadamente o dobro dos obtidos em seus trechos superiores. O Brejal se destaca com diferença significativa entre os trechos analisados, estando o SL mais elevado vinculado à principal ruptura de declive também observada no rio Bonito principal, como observado anteriormente. Esses valores se apresentam invertidos no canal identificado como Soledade, estando com índice mais elevado em seus trecho superior e não no trecho inferior. Os índices SL mais baixos podem estar relacionados à ocorrência de vales suspensos com extensas planícies aluvionares desenvolvidas nesse compartimento escalonado e com canais mais longos, como indicado pela condição de assimetria da bacia de drenagem (MENDES et al., 2007). Essa sedimentação promovida pela geração de knickpoints nesses canais e formação dos extensos alvéolos parece influenciar o perfil de equilíbrio desses canais e, portanto, os índices SL, especialmente no Soledade Inferior. 


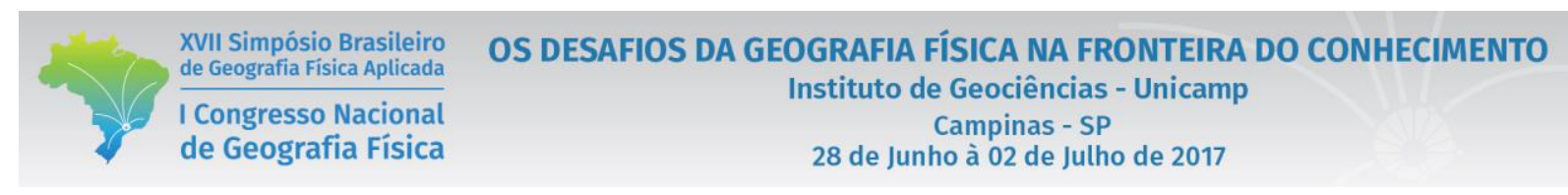

Tabela 1 - Resultados índice de gradiente de canal - SL Total

\begin{tabular}{|c|c|c|c|c|c|c|}
\hline Identificação & $\begin{array}{c}\text { Distância } \\
\text { divisor (m) }\end{array}$ & $\begin{array}{l}\text { Elevação } \\
\text { Máx. (m) }\end{array}$ & $\begin{array}{l}\text { Elevação } \\
\text { Mín. (m) }\end{array}$ & $\begin{array}{c}\text { Extensão } \\
\text { total (l) (m) }\end{array}$ & $\begin{array}{l}\text { Declividade } \\
\text { (h/l) }\end{array}$ & SL \\
\hline Rio Bonito (Principal) & 500 & 1300 & 500 & 18200 & 0,0440 & 422 \\
\hline $\begin{array}{l}\text { Rio Bonito Cabeceira } \\
\text { Maria Antônia }\end{array}$ & 450 & 1400 & 1000 & 4650 & 0,0860 & 239 \\
\hline $\begin{array}{c}\text { Rio Bonito Cabeceira } \\
\text { Taquaril }\end{array}$ & 100 & 1200 & 900 & 3600 & 0,0833 & 158 \\
\hline Córrego Soledade & 63 & 1200 & 888 & 4900 & 0,0637 & 160 \\
\hline Córrego Nunes & 86 & 1100 & 879 & 4350 & 0,0508 & 115 \\
\hline Córrego Matilde & 57 & 1010 & 879 & 4700 & 0,0279 & 67 \\
\hline Córrego Brejal & 159 & 1100 & 515 & 8050 & 0,0727 & 304 \\
\hline
\end{tabular}

Tabela 2 - Resultados índice de gradiente de canal (SL) por trecho

\begin{tabular}{|c|c|c|c|c|c|c|}
\hline Identificação & $\begin{array}{c}\text { Distância } \\
\text { divisor (m) }\end{array}$ & $\begin{array}{l}\text { Elevação } \\
\text { Máx. (m) }\end{array}$ & $\begin{array}{l}\text { Elevação } \\
\text { Mín. (m) }\end{array}$ & $\begin{array}{c}\text { Extensão } \\
\text { total (l) (m) }\end{array}$ & $\begin{array}{c}\text { Declividade } \\
\text { (h/l) }\end{array}$ & SL \\
\hline Rio Bonito Superior & 500 & 1300 & 879 & 9100 & 0,0463 & 234 \\
\hline Rio Bonito Inferior & 500 & 879 & 500 & 9100 & 0,0416 & 421 \\
\hline $\begin{array}{c}\text { Rio Bonito Maria Antônia } \\
\text { Superior }\end{array}$ & 450 & 1400 & 1150 & 2325 & 0,1075 & 173 \\
\hline $\begin{array}{c}\text { Rio Bonito Maria Antônia } \\
\text { Inferior }\end{array}$ & 450 & 1150 & 1000 & 2325 & 0,0645 & 208 \\
\hline Soledade Superior & 63 & 1200 & 890 & 2450 & 0,1265 & 163 \\
\hline Soledade Inferior & 63 & 890 & 888 & 2450 & 0,0008 & 2 \\
\hline Nunes Superior & 86 & 1100 & 983 & 2150 & 0,0544 & 63 \\
\hline Nunes Inferior & 86 & 983 & 879 & 2150 & 0,0486 & 112 \\
\hline Matilde Superior & 57 & 1010 & 950 & 2350 & 0,0255 & 31 \\
\hline Matilde Inferior & 57 & 950 & 879 & 2350 & 0,0302 & 74 \\
\hline Brejal Superior & 159 & 1100 & 1020 & 4025 & 0,0199 & 43 \\
\hline Brejal Inferior & 159 & 1020 & 515 & 4025 & 0,1255 & 545 \\
\hline
\end{tabular}

\section{Conclusões}

A análise geomorfométrica proposta para a bacia hidrográfica do rio Bonito, a partir dos índices de gradiente dos canais de drenagem, permitiu identificar que os índices SL mais elevados coincidem com as marcantes rupturas observadas nos perfis longitudinais dos canais, principalmente no setor superior da bacia de drenagem (SLTotal) e outros localizados nos cursos 


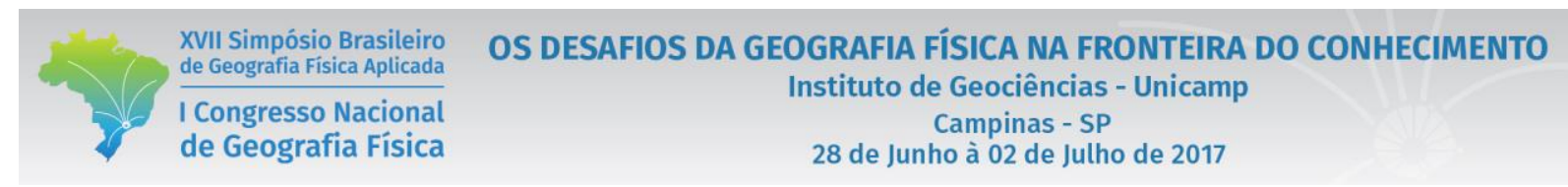

inferiores dos rios (SL Trecho). Destaca-se o Brejal pelo alto índice $(\mathrm{SL}=545)$ em seu curso inferior, vinculado à mesma condição do Rio Bonito principal $(\mathrm{SL}=421)$, área da mais expressiva ruptura de declive observada e associada à existência de um alto topográfico, como indicado em estudos anteriores. Os valores de SL menos elevados estão em contexto de vales suspensos, com extensas planícies aluvionares e que podem justificar as diferenças observadas.

Os resultados evidenciam a condição de desequilíbrio do sistema fluvial, influenciada pelo controle tectônico-estrutural observado na sua compartimentação morfotectônica e, portanto, pela evolução geológico-geomorfológica da área.

\section{Bibliografia}

ALMEIDA, J.C.H. Zonas de cizalhamento dúctil de alto grau do Médio Vale do Rio Paraíba do Sul. 2000. 201 f. Tese (Doutorado-Geologia), UNESP, Rio Claro.

ETCHEBEHERE, M. L.; SAAD, A.R.; FÚLFARO, V.J. PERINOTTO, J.A.J. Aplicação do índice "Relação DeclividadeExtensão - RDE" na Bacia do Rio do Peixe (SP) para detecção de deformações neotectônicas. Geologia USP Série Científica, São Paulo, v. 4, n. 2, p. 43-56, 2004.

HACK, J.T. Stream profile analysis and stream gradient index. Journal Research US Geol. Survey, v.1, n.4, p.421429, 1973.

HEILBRON, M.; VALERIANO, C.M.; TUPINAMBÁ, M. \& ALMEIDA, J.C.H. An evolutionary tectonic model for the central Ribeira Belt: from Transamazonian collage to Gondwana amalgamation. In: Simpósio Nacional de Estudos Tectonicos, 7., 1999, Lençóis, Anais... SBG, 1999. p.58-61.

MENDES, L. D.; FERNANDES, N. F.; GONTIJO-PASCUTTI, A. H. F. Morfotectônica da bacia hidrográfica do rio Bonito, Petrópolis, RJ. Revista Brasileira de Geomorfologia, ano 8, n 1, 2007.

SILVA, T.M. A estruturação geomorfológica do Planalto Atlântico no Estado do Rio de Janeiro. 2002. 264 f. Tese (Doutorado em Geografia), Universidade Federal do Rio de Janeiro, Rio de Janeiro.

THOMAS, D.S.G.; ALLISON, R.J. (Eds.) Landscape Sensitivity. Chichester: John Wiley and Sons, 1993. 347 p.

ZHANG, W.; HAYAKAWA, Y.S.; OGUCHI, T. DEM and GIS based morphometric and topographic-profile analyses of Danxia landforms. In: Geomorphometry, 2011. Disponível em $<$ http://geomorphometry.org/Zhang2011 $>$ Acesso em 13 de fevereiro de 2017. 